\title{
Effect of Y-aminobutyric acid-rich yogurt on insulin sensitivity in a mouse model of type 2 diabetes mellitus
}

\author{
Xiangfei Li, ${ }^{1,2 *}$ () Lin Chen, ${ }^{2 *}$ Xiaoyu Zhu, ${ }^{2}$ Zhaoxin $\mathrm{Lu}^{2}{ }^{2} \dagger$ 이 and Yingjian $\mathrm{Lu}^{1} \dagger$ \\ ${ }^{1}$ College of Food Science and Engineering, Nanjing University of Finance and Economics, Nanjing 210023, P. R. China \\ ${ }^{2}$ College of Food Science and Technology, Nanjing Agricultural University, Nanjing 210095, P. R. China
}

\begin{abstract}
This study aimed to investigate the effect of a $\gamma$-aminobutyric acid (GABA)-rich yogurt fermented with Streptococcus thermophilus fmb-5 on insulin sensitivity in high-fat and low-dose streptozotocin-induced type 2 diabetes mellitus mice. To study the ability of the yogurt to enhance insulin sensitivity, diabetic mice were treated with $0.5,1$, or $2 \mathrm{~g} / \mathrm{L}$ of GABA yogurt once a day from wk 1 to 12 . Compared with results in untreated diabetic mice, treatment with different dosages of GABA yogurt was associated with increased serum insulin and fat coefficient (fat weight relative to body weight) levels, decreased blood urea nitrogen, kidney coefficient (kidney weight relative to body weight), glucose area under the curve levels, and insulin sensitivity index, but did not alter blood glucose level or body weight. The highest dosage of GABA yogurt had a greater beneficial effect with respect to insulin resistance than the lower dosages. In particular, dietary supplementation of the high dosage of GABA yogurt favorably regulated HOMA- $\beta$ (homeostasis model assessment of $\beta$-cell function), total cholesterol, high-density lipoprotein cholesterol, fat coefficient, and improved islet cells morphology. These results demonstrated that $2 \mathrm{~g} / \mathrm{L}$ GABA yogurt could ameliorate insulin sensitivity. The GABA-rich yogurts appeared to be responsible for health-beneficial effects in this mouse model of diabetes.
\end{abstract}

Key words: glucose intolerance, $\gamma$-aminobutyric acid (GABA)-rich yogurt, organ coefficient, diabetes

Received October 16, 2019.

Accepted March 24, 2020.

*These authors contributed equally to this work.

$\dagger$ Corresponding authors: fmb@njau.edu.cn and yingjianlu@nufe.edu

\section{INTRODUCTION}

Type 2 diabetes mellitus (T2DM) is a complex disease associated with defects in insulin secretion or action of insulin (American Diabetes Association, 2011; Manaer et al., 2015). Insulin resistance is a defect in insulin action, specifically, a reduced ability of insulin to regulate glucose homeostasis in adipose tissue, liver, and skeletal muscle, among others (Kahn, 2003). Type 2 diabetes mellitus with central pathological obesity is characterized by insulin resistance (Xie et al., 2015). Insulin resistance also causes T2DM-related complications (Salas-Salvadó et al., 2011). Individuals with $\mathrm{T} 2 \mathrm{DM}$ suffer from a long-term impairment, dysfunction, and failure of different organs, including eyes, kidneys, nerves, heart, feet, and blood vessels (American Diabetes Association, 2013; Li et al., 2016a). In addition, T2DM has been associated with neurocognitive disorders (Jones et al., 2014). Not surprisingly, reduced insulin concentrations and abnormal insulin receptor function and density in the brain have also been associated with many other metabolic diseases (Biessels et al., 2002; Thielen et al., 2019).

$\gamma$-Aminobutyric acid (GABA) is a major inhibitory neurotransmitter in the central nervous system; it is produced by $\beta$-cells and synthesized through the conversion of L-glutamate by glutamic acid decarboxylase (Kittler and Moss, 2003). Administration of GABA may be an efficient therapeutic strategy for T2DM. For instance, dietary supplementary of GABA-producing Lactobacillus brevis DPC 6108 attenuated hyperglycemia in streptozotocin (STZ)-induced diabetic Sprague Dawley rats (Marques et al., 2016). A previous study showed that GABA exerted antidiabetic effects mainly through $\beta$-cell mass restoration and systemic inflammatory cytokine production (Soltani et al., 2011). As a signaling molecule in pancreatic islets, interstitial GABA activates $\mathrm{GABA}_{\mathrm{A}}$ channels and $\mathrm{GABA}_{\mathrm{B}}$ receptors, which modulate insulin and glucagon release in pancreatic islets in individuals with type 2 diabetes (Taneera et al., 2012). 
Various findings have indicated that GABA could be function against insulin resistance by the activation of GABA receptors (Soltani et al., 2011; Taneera et al., 2012; Daems et al., 2019). Enhancing insulin sensitivity is an efficient strategy to treat T2DM and may represent an approach by which to research drugs for hypoglycemia. $\gamma$-Aminobutyric acid has an insulinotropic effect in humans, as well as $\beta$-cell regenerative and immunoinhibitory effects, and thus might regulate islet cell function and glucose and insulin homeostasis (Soltani et al., 2011). Oral treatment with GABA was shown to inhibit BW gain and improve glucose tolerance and insulin sensitivity in mice fed a high-fat diet (Tian et al., 2011). It has been shown that GABA exerts fat depot-selective suppression of inflammatory responses and protection from insulin resistance, which may be a consequence of reduced monocyte migration in subcutaneous inguinal adipose tissue (Hwang et al., 2019).

Recent studies have suggested that dietary supplementation with probiotics can preserve diet-induced insulin sensitivity in T2DM mice (Andreasen et al., 2010; Naito et al., 2011; Li et al., 2016a). In addition, GABA is correlated with increasing mass of pancreatic $\beta$-islets and suppressing subcutaneous adipose production in type 1 diabetes and obesity mice (Daems et al., 2019; Hwang et al., 2019). Hence, we investigated the beneficial effects of GABA-rich yogurt on insulin sensitivity in diabetic mice, which is related to pancreatic $\beta$-islets and adipose tissue. We aimed to explore whether GABA-rich yogurt could improve insulin sensitivity in a high-fat and STZ-induced T2DM model in mice. To examine the pancreas and adipose tissues that are crucial in the regulation of insulin sensitivity in a mouse model, we investigated the effects of different doses of GABA-yogurt in diabetic mice.

\section{MATERIALS AND METHODS}

\section{Preparation of GABA-Rich Yogurt}

Streptococcus thermophilus fmb5 can catalyze the decarboxylation of glutamate to GABA; it was used as a yogurt starter and was activated twice at $37^{\circ} \mathrm{C}$ with a skim milk preculture. Then, $2 \%$ (vol/vol) of the mixture was inoculated into de Man, Rogosa, and Sharpe broth for seed liquid preparation. Skim milk medium was mixed with $1.2 \%$ sodium glutamate, sterilized in an autoclave for $5 \mathrm{~min}$ at $115^{\circ} \mathrm{C}$, and cooled to $42^{\circ} \mathrm{C}$. The sterile mixture was then inoculated with $2 \%$ seed liquid and fermented at $37^{\circ} \mathrm{C}$ for $72 \mathrm{~h}$. Subsequently, the fermented GABA-rich yogurt $(\mathrm{pH}=4.0$, GABA concentration $=7.3 \mathrm{~g} / \mathrm{L}$ ) was stored at $-80^{\circ} \mathrm{C}$ until further use. The yogurt was diluted with purified water to achieve GABA concentrations of $0.5,1$, and $2 \mathrm{~g} / \mathrm{L}$ before use.

\section{Experimental Animals}

Mice and Intervention Protocol. All animal experimental procedures received approval from the Animal Ethics Committee of Nanjing Agricultural University, China (SYXK 2017-0007). Fifty-six 4-wkold specific-pathogen-free male C57BL/6J mice were purchased from the Model Animal Research Center of Nanjing University (Najing, China). All mice were housed in a controlled environment at constant temperature $\left(22^{\circ} \mathrm{C} \pm 2^{\circ} \mathrm{C}\right)$ and humidity $(55 \% \pm 5 \%)$, using a 12-h light-dark cycle. In the first week, mice were allowed free access to food and water and divided into 7 groups $(\mathrm{n}=8)$.

After acclimation, 8 mice were fed a normal diet and water as the control group $(\mathbf{C O N})$; the others were fed a high-fat diet and administered water (diabetes model, DM group), $10 \mathrm{mg} / \mathrm{kg}$ melbine (positive control, DMBG group), yogurt without GABA (YG group), $0.5 \mathrm{~g} / \mathrm{L}$ GABA yogurt (low-dose GABA, LG group), 1 g/L GABA yogurt (medium-dose GABA, MG group), or $2 \mathrm{~g} / \mathrm{L}$ GABA yogurt (high-dose GABA, HG group). After 4 wk of dietary manipulation, all mice were fasted for $12 \mathrm{~h}$ and received a intraperitoneal injection of STZ in citrate buffer or citrate buffer alone. Mice fed the high-fat diet were injected with STZ (Sigma Chemical Co., St. Louis, MO) freshly dissolved in $50 \mathrm{mmol} / \mathrm{L}$ citrate buffer at $100 \mathrm{mg} / \mathrm{kg}$ of $\mathrm{BW}$ to induce T2DM, whereas mice in the CON group (fed a normal diet) received an equivalent volume of citrate buffer. From wk 4 to 12 , the mice in the 6 treatment groups were given a high-fat chow and mice in the CON group remained on the normal diet (Figure 1).

Blood Glucose Index. Fasting blood glucose (FBG) of mice was measured monthly using the Onetouch Ultraeasy glucometer (Johnson (China) Medical Materials Co. Ltd., Shenzhen, China) on samples collected from the tip of the tail vein. At wk 9 , mice in the DM group with FBG $\geq 11.1 \mathrm{mmol} / \mathrm{L}$ were confirmed as T2DM mice (Gao et al., 2015).

Oral Glucose Tolerance Test and Areas Under the Curve. For the oral glucose tolerance test (OGTT), mice were fasted for $12 \mathrm{~h}$ and then orally administered glucose $(2 \mathrm{~g} / \mathrm{kg}$ of BW) at wk 12. Blood glucose levels were recorded for $0,30,60$, and $120 \mathrm{~min}$ after glucose administration. The total glucose area under the curve $\left(\mathbf{A U C}_{\text {glucose }}\right)$ was calculated according to the trapezoidal rule.

Serum Biochemical Analysis, Organ Coefficients, and Histological Analysis. Serum total cholesterol (TC), triacylglycerols (TG), high-density 


\section{Intraperitoneally injected}

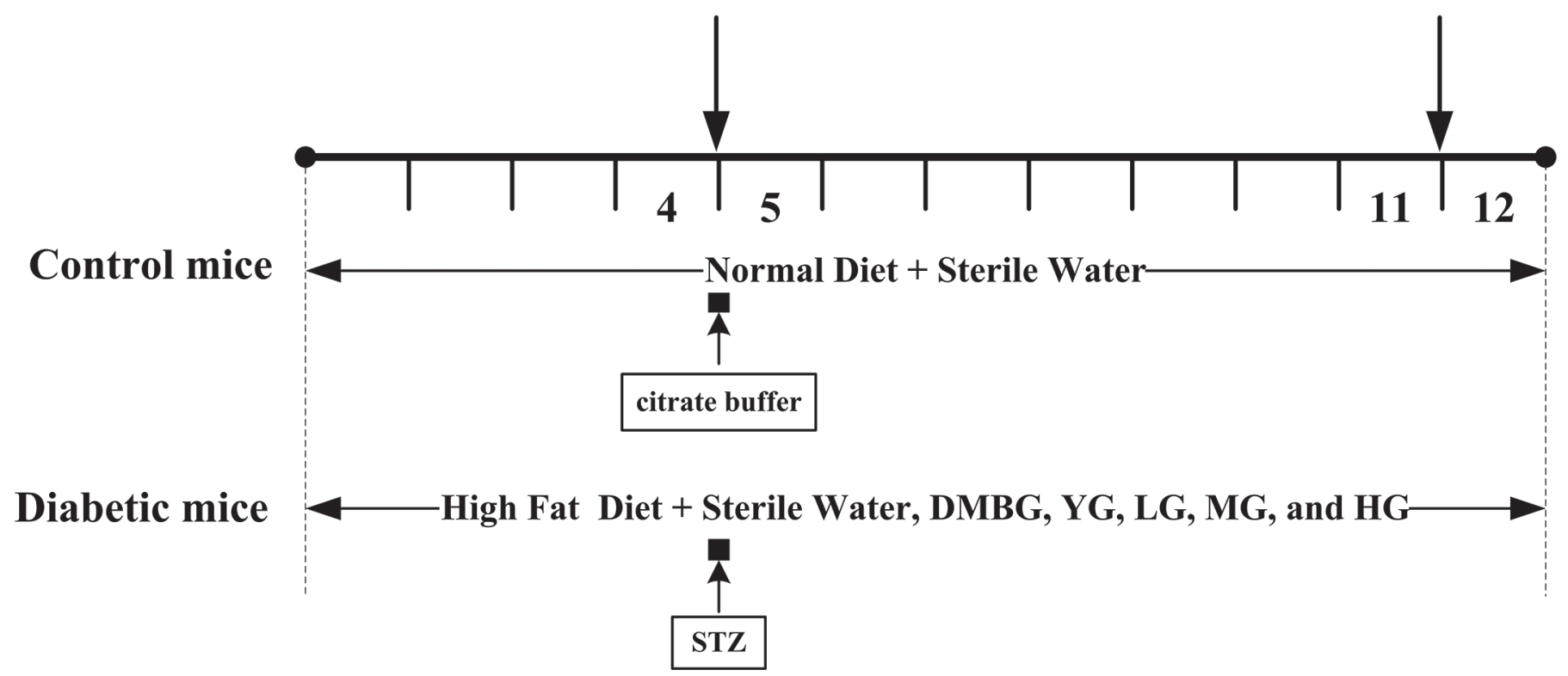

Figure 1. Animal experimental design showing treatments and assessments administered over a 12-wk period to control mice and diabetic mice induced using streptozotocin (STZ) after 4 wk. OGTT $=$ oral glucose tolerance test; CON $=$ normal diet and water; DM $=$ high-fat diet and water; DMBG = high-fat diet plus melbine; YG = high-fat diet plus yogurt without $\gamma$-aminobutyric acid $(\mathrm{GABA}) ; \mathrm{LG}=$ high-fat diet plus yogurt with low-dose GABA $(0.5 \mathrm{~g} / \mathrm{L}) ; \mathrm{MG}=$ high-fat diet plus yogurt with medium-dose GABA $(1 \mathrm{~g} / \mathrm{L})$; HG = high-fat diet plus yogurt with high-dose GABA $(2 \mathrm{~g} / \mathrm{L})$.

lipoprotein cholesterol (HDL-C), and low-density lipoprotein cholesterol (LDL-C), and BUN were measured using commercial kits. Glycated hemoglobin (HbA1C) wAS measured using ELISA kits (Nanjing Jiancheng Biology Engineering Institute, Nanjing, China). Fasting serum insulin (FINS) was measured using ELISA kits (R\&D Systems Inc., Minneapolis, MN). Indices were calculated as follows:

Insulin sensitivity index $($ ISI $)=\ln (1 /$ FINS $\times$ FBG $)$;

Homeostasis model assessment- $\beta$ (HOMA- $\boldsymbol{\beta})=$

$$
(20 \times \mathrm{FINS}) /(\mathrm{FBG}-3.5) ;
$$

Insulin resistance index (HOMA-IR $)=$

$$
\mathrm{FINS} \times \mathrm{FBG} / 22.5 .
$$

The HOMA-IR index followed Haffner et al. (2002). Organ coefficients were calculated as follows: organ coefficient $=$ organ weight $/ \mathrm{BW}(\mathrm{mg} / \mathrm{g}$ of BW).

Pancreas tissue was mixed with $4 \%$ polyformaldehyde solution for $24 \mathrm{~h}$, dehydrated in graded alcohol, cleared in xylene, and embedded in paraffin blocks. The blocks were sectioned at $5 \mu \mathrm{m}$ and stained with hematoxylin and eosin. Slides were scanned using a pathologic slice scanner (Pannoramic MIDI, 3DHISTECH, Budapest, Hungary).

\section{Statistical Analysis}

All data are presented as mean \pm SEM. The GraphPad Prism 5 (GraphPad Inc., San Diego, CA) was used in the analysis of experimental results. Groups were analyzed using one-way ANOVA followed by Tukey's test. $P<0.05$ was considered significant. Every test was repeated 3 times.

\section{RESULTS}

\section{Effect of Different Dosages of GABA Yogurt on $B W$ and $F B G$}

The BW and FBG changes of all the mice were measured once every $4 \mathrm{wk}$, starting $7 \mathrm{~d}$ after STZ injection. Figure 2A shows the BW of all groups. Compared with the CON group, the BW of diabetic mice was lower than that of the CON group. Oral supplementation of GABA-yogurt showed no significant increase in body weight. Figure $2 \mathrm{~B}$ shows the changes in FBG of all 

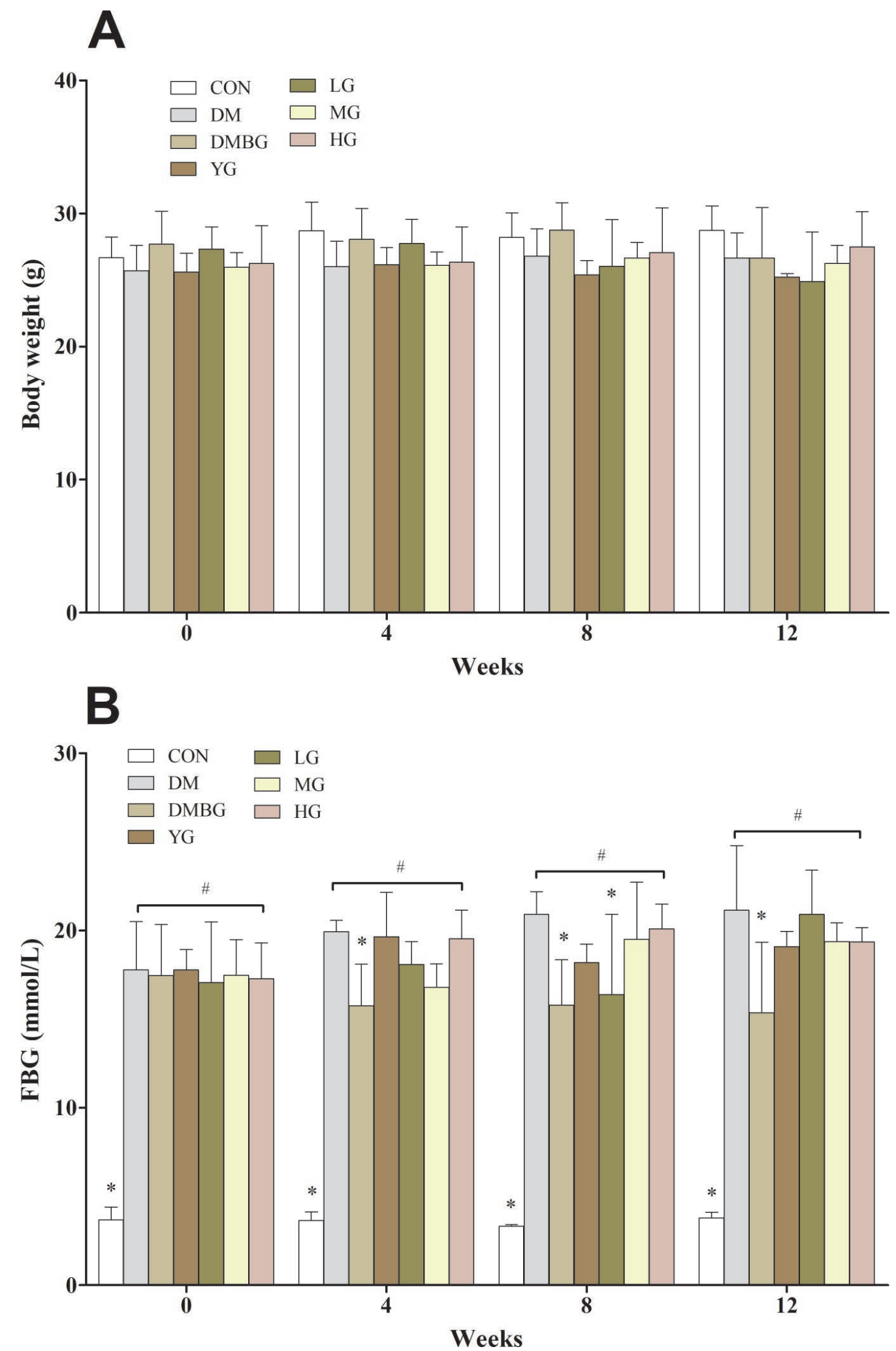

Figure 2. Effect of different dosages of $\gamma$-aminobutyric acid (GABA) yogurt on BW (A) and fasting blood glucose (FBG; B). Values are the mean \pm SEM $(\mathrm{n}=8)$. $\# P<0.05$ versus the $\mathrm{DM}$ group; ${ }^{*} P<0.05$ versus the $\mathrm{CON}$ group. $\mathrm{CON}=$ normal diet and water; $\mathrm{DM}=$ high-fat diet and water; DMBG = high-fat diet plus melbine; $\mathrm{YG}=$ high-fat diet plus yogurt without GABA; LG = high-fat diet plus yogurt with low-dose GABA (0.5 g/L); MG = high-fat diet plus yogurt with medium-dose GABA (1 g/L); HG = high-fat diet plus yogurt with high-dose GABA (2 $\mathrm{g} / \mathrm{L})$. 
groups. As expected, FBG in the DM group (17.78 $\mathrm{mmol} / \mathrm{L}$ ) was significantly higher than that of the CON group $(3.70 \mathrm{mmol} / \mathrm{L})$ and was $>11.1 \mathrm{mmol} / \mathrm{L}$ at $7 \mathrm{~d}$ after STZ injection, confirming successful induction of diabetes $(P<0.05$, Figure 2B). Supplementation of DMBG to the diabetic mice had a positive effect on hypoglycemic activity $(P<0.05$, Figure $2 \mathrm{~B})$. However, the FBG levels of mice in the DM, LG, MG, and HG groups showed no significant differences.

\section{Effect of Different Dosages of GABA Yogurt on OGTT and AUC $C_{\text {glucose }}$}

At wk 12, an OGTT was performed in overnightfasted mice of all groups. Blood glucose levels at 0, 30, 60, and 120 min and $\mathrm{AUC}_{\text {glucose }}$ are shown in Figure 3. At all time points, the blood glucose levels of diabetic mice were higher than that of control mice (Figure 3A). Oral administration of different dosages of GABA yogurt revealed a numeric decrease in blood glucose at 30,60, and $120 \mathrm{~min}$, but these values did not differ significantly compared with that in the DM and CON groups (Figure $3 \mathrm{~A})$. The $\mathrm{AUC}_{\text {glucose }}$ in the $\mathrm{DMBG}, \mathrm{YG}$, LG, MG, and HG groups decreased significantly compared with that in the DM and CON groups $(P<0.05$, Figure $3 \mathrm{~A})$.

\section{Effect of Different Dosages of GABA Yogurt on HbA1C, Insulin, and BUN Levels}

The concentration of HbA1C is an important index of T2DM, and can reflect average blood glucose levels within 2 month. Fasting blood insulin content is a means to measure and evaluate the function of islet $\beta$ cells. Blood urea $\mathrm{N}$ is one of the main indicators of renal function. The levels of serum $\mathrm{HbA1C}$, insulin, and BUN in the DM group were significantly different from those in the CON group $(P<0.05$, Figure $4 \mathrm{~A}, 4 \mathrm{~B}$, and $4 \mathrm{C})$. Supplementation of different dosages of GABA yogurt increased insulin and decreased BUN close to the levels of the CON group $(P<0.05$, Figure $4 \mathrm{~B}$ and $4 \mathrm{C})$. The levels of $\mathrm{HbA1C}$ in the $\mathrm{LG}, \mathrm{MG}$, and $\mathrm{HG}$ groups were not significantly different from that in the DM group $(P<0.05$, Figure $4 \mathrm{~A})$.

\section{Effect of Different Dosages of GABA Yogurt on Insulin Sensitivity}

We evaluated the effects of GABA yogurt on insulin sensitivity. Treatment with different dosages of GABA yogurt in diabetic mice decreased ISI $(P<0.05$, Figure $5 \mathrm{~A})$. The HOMA-IR and HOMA- $\beta$ of all diabetic mice were significantly different from those of control mice $(P<0.05$, Figure 5B and 5C). The HOMA-IR remained high in the LG, MG, and HG groups compared with the CON group $(P<0.05$, Figure 5B). However, the levels of HOMA- $\beta$ in the MG and HG groups were significantly higher than that in the DM group $(P<$ 0.05, Figure 5C).

\section{Effect of Different Dosages of GABA Yogurt on Serum Lipid}

As shown in Figure 6, mice in the DM group had markedly higher concentrations of TC $(6.21 \mathrm{mmol} / \mathrm{L})$, TG $(2.29 \mathrm{mmol} / \mathrm{L})$, and LDL-C $(3.52 \mathrm{mmol} / \mathrm{L})$ and lower concentrations of HDL-C $(1.43 \mathrm{mmol} / \mathrm{L})$ than mice in the CON group $(P<0.05$, Figure $6 \mathrm{~A}, 6 \mathrm{~B}$, and $6 \mathrm{D})$. Mice in the YG, LG, and MG groups had an altered composition of serum lipids, with higher TC and TG and lower LDL-C compared with mice in the CON group $(P<0.05$, Figure $6 \mathrm{~A}, 6 \mathrm{~B}$, and $6 \mathrm{D})$. The $\mathrm{HG}$ treatment led to a significant reduction in the levels of TC and LDL-C $(P<0.05$, Figure $6 \mathrm{~A}$ and $6 \mathrm{D})$. Mice in the DMBG had decreased TG concentrations $(P<$ 0.05 , Figure $6 \mathrm{~B}$ ). The level of HDL-C in the HG group was markedly higher than that in the DM group $(P<$ 0.05, Figure 6C).

\section{Effect of Different Dosages of GABA Yogurt on Organ Coefficients}

A high-fat diet and STZ-induced diabetes significantly increased the fat, kidney, and heart coefficients, and reduced the coefficients of liver and thymus $(P<0.05$, Figure 7). Oral supplementation of different dosages of GABA yogurt all recovered the fat, liver, and kidney coefficients compared with those in the DM group $(P<$ 0.05, Figure 7A, 7B, and 7C). However, the coefficients of heart, spleen, and thymus in the LG, MG, and HG group did not differ from that of the DM group $(P>$ 0.05 , Figure 7D, 7E, and 7F).

\section{Effect of Different Dosages of GABA Yogurt on Histopathology of the Pancreas}

Hematoxylin and eosin staining of the pancreas suggested that the shape and number of pancreatic islet cells in the DMBG, YG, LG, MG, and HG groups showed an improvement in islet morphology, compared with the large, round Langerhans islets with clear boundaries in the CON group (Figure $8 \mathrm{C}, 8 \mathrm{D}, 8 \mathrm{E}, 8 \mathrm{~F}$, and $8 \mathrm{G}$ ). In the pancreas of mice in the different GABA yogurt groups, especially HG, the shape of the islets 
was restored, being similar to that of the CON group, and a greater number of central particles was observed compared with that of the DM group. In addition, mice in the DMBG, YG, and HG groups showed better recovery of islet cells compared with those in the LG and MG groups.

\section{DISCUSSION}

Supplementation with GABA effectively modulates hormone release in islets from humans and mice with type 2 diabetes by activating $\mathrm{GABA}_{\mathrm{A}}$ channels and $\mathrm{GABA}_{\mathrm{B}}$ receptors (Kittler and Moss, 2003; Taneera et al., 2012; Feng et al., 2017). Supplementation of rats with a GABA-producing Lactobacillus brevis DPC 6108
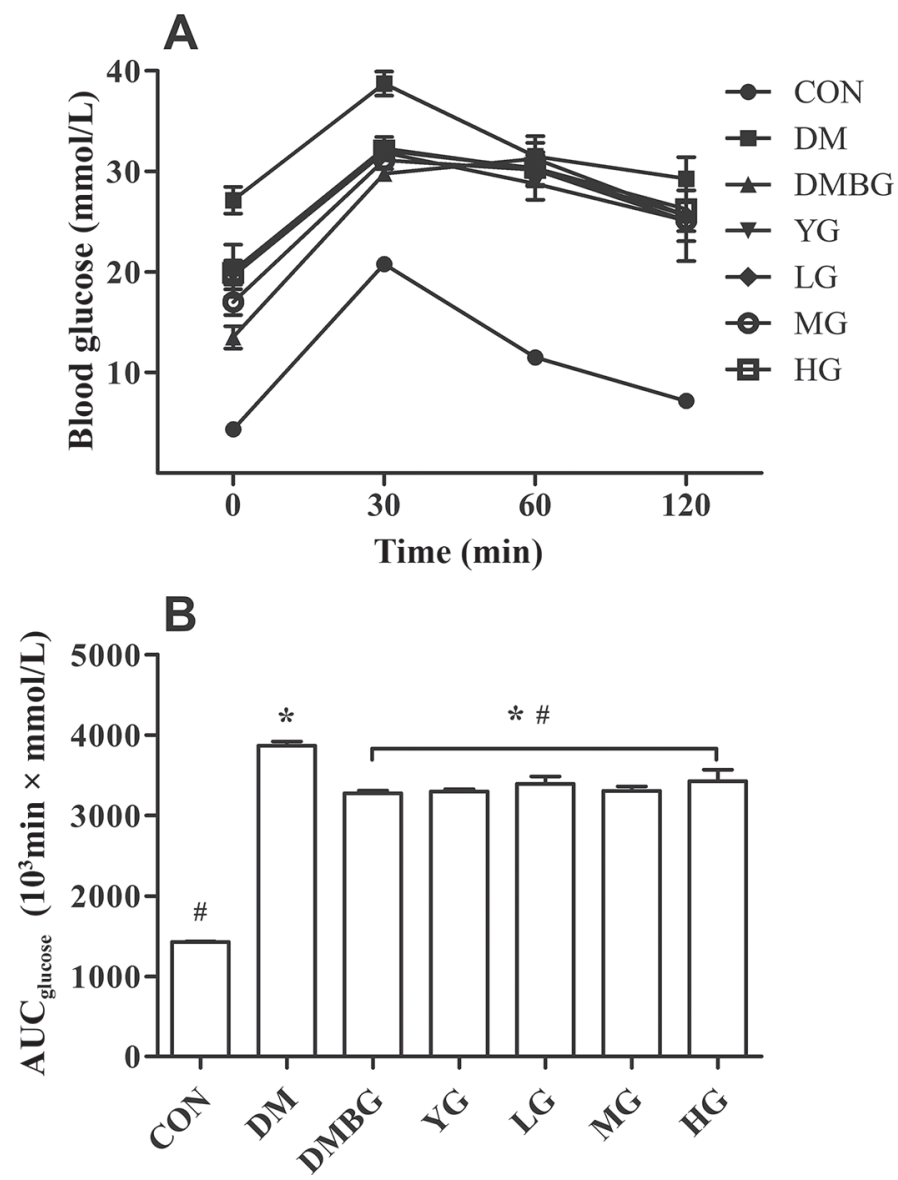

Figure 3. Effect of different dosages of $\gamma$-aminobutyric acid (GABA) yogurt on (A) oral glucose tolerance test (measured as blood glucose) and $(\mathrm{B})$ glucose area under the curve $\left(\mathrm{AUC}_{\text {glucose }}\right)$. Values are the mean \pm SEM $(\mathrm{n}=8)$. $\# P<0.05$ versus the $\mathrm{DM}$ group; ${ }^{*} P<0.05$ versus the $\mathrm{CON}$ group. $\mathrm{CON}=$ normal diet and water; $\mathrm{DM}=$ highfat diet and water; $\mathrm{DMBG}=$ high-fat diet plus melbine; $\mathrm{YG}=$ highfat diet plus yogurt without GABA; LG = high-fat diet plus yogurt with low-dose GABA $(0.5 \mathrm{~g} / \mathrm{L}) ; \mathrm{MG}=$ high-fat diet plus yogurt with medium-dose GABA ( $1 \mathrm{~g} / \mathrm{L}) ; \mathrm{HG}=$ high-fat diet plus yogurt with high-dose GABA (2 g/L).
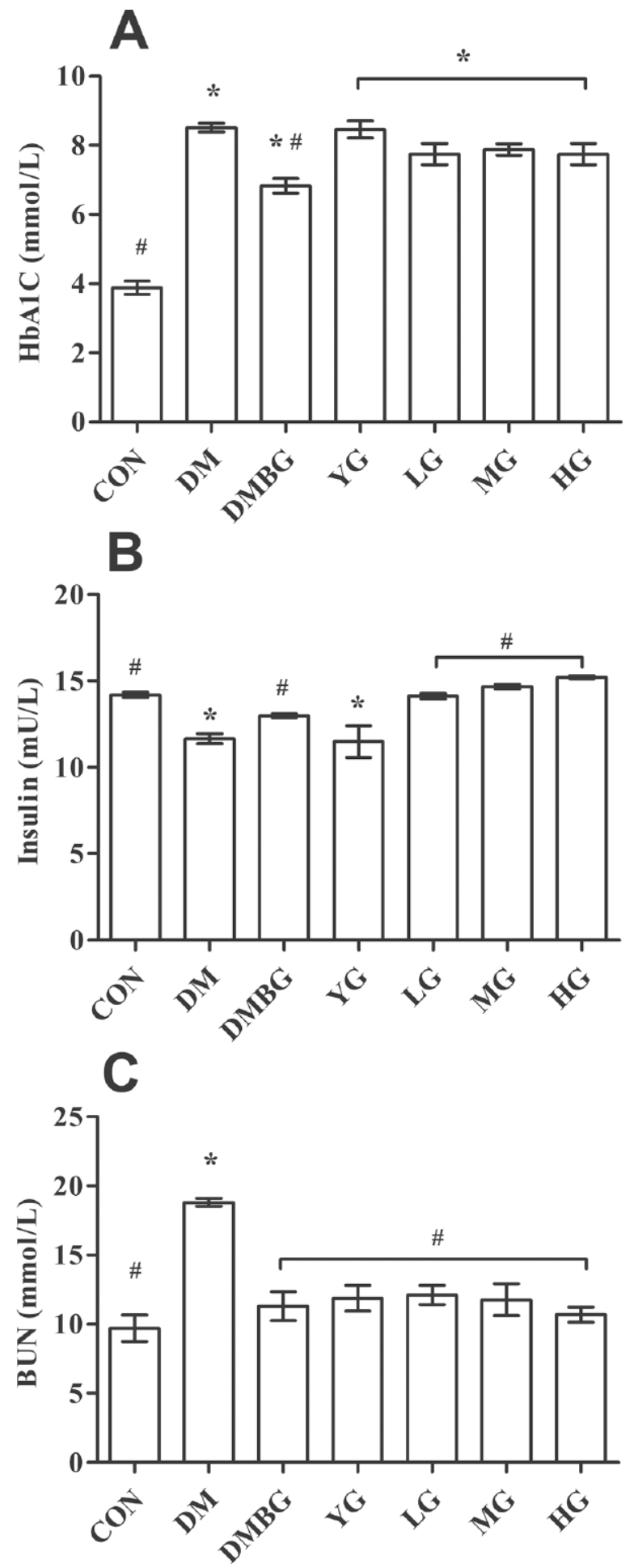

Figure 4. Effect of different dosages of $\gamma$-aminobutyric acid (GABA) yogurt on (A) glycated hemoglobin (HbA1C), (B) insulin, and $(\mathrm{C})$ BUN levels. Values are the mean $\pm \operatorname{SEM}(\mathrm{n}=4)$. $\# P<$ 0.05 versus the DM group; $* P<0.05$ versus the $\mathrm{CON}$ group. $\mathrm{CON}=$ normal diet and water; $\mathrm{DM}=$ high-fat diet and water; $\mathrm{DMBG}=$ highfat diet plus melbine; YG = high-fat diet plus yogurt without GABA; $\mathrm{LG}=$ high-fat diet plus yogurt with low-dose GABA $(0.5 \mathrm{~g} / \mathrm{L}) ; \mathrm{MG}$ $=$ high-fat diet plus yogurt with medium-dose GABA $(1 \mathrm{~g} / \mathrm{L}) ; \mathrm{HG}=$ high-fat diet plus yogurt with high-dose GABA $(2 \mathrm{~g} / \mathrm{L})$. 
modulated glucose levels and microbial diversity attenuated hyperglycemia induced by diabetes (Marques et al., 2016). Our previous studies showed that $L$. casei CCFM419 and a multi-species probiotic had a protective effect in relieving insulin resistance and type 2 diabetes by modifying the gut microbiota and transforming short-chain fatty acids, in turn enhancing the inflammatory response and promoting secretion of glucagon-like peptide-1 (GLP-1) (Li et al., 2016b, 2017; Wang et al., 2017). In addition, other studies have confirmed that GABA and GABA-producing Lactobacillus brevis DPC 6108 ameliorated hypoglycemia and insulin resistance, which is associated with islet $\beta$-cells, immune system, and inguinal adipose tissue (Soltani et al., 2011; Marques et al., 2016; Hwang et al., 2019). In this study, we explored whether the insulin resistance activity helped to repair islet $\beta$-cells and adipose tissue in diabetic mice.

Our results demonstrated that different doses of GABA yogurt partially alleviated symptoms of diabetes in a mouse model. However, supplementation with the 2 higher doses of GABA (MG and HG groups) significantly regulated glucose tolerance, serum lipid metabolism, insulin resistance, and fat coefficient. In addition, the beneficial effects of HG on serum lipid levels and pancreatic islet cells were more pronounced than those with other dosages. These results were consistent with high-dose GABA and L. brevis DPC 6108-treated diabetic mice (Marques et al., 2016). Moreover, GABA was shown to suppress subcutaneous adipose and protect against insulin resistance in obese mice (Hwang et al., 2019). The changes observed in fat and liver coefficients may contribute to dyslipidemia, which is a common characteristic in T2DM (Li et al., 2014). It is well known that dyslipidemia is closely related to insulin resistance (Zhao et al., 2014). Oral administration of HG and MG significantly decreased the fat coefficient and increased the liver coefficient. The changes in ISI and HOMA- $\beta$ might be a consequence of dyslipidemia recovery in the HG and MG groups.

Impairment of $\beta$-cell function and decreased insulin levels result from the destruction of pancreatic $\beta$-cells (Daems et al., 2019). The resurgence of the pancreas leads to lower glucose tolerance and increased insulin sensitivity. In type 1 diabetes mouse models, GABA has been shown to promote $\beta$-cell proliferation and protect $\beta$-cells from apoptosis and thus reverse diabetes (Soltani et al., 2011). In agreement with the previous studies, the consumption of HG in this study had a pronounced effect on the restoration of pancreatic islet cells. Recovery of islets could effectively regulate insulin levels, alleviate glucose intolerance, and lead to development of insulin sensitivity. The GABA yogurt played a dominant role in promoting insulin production, which
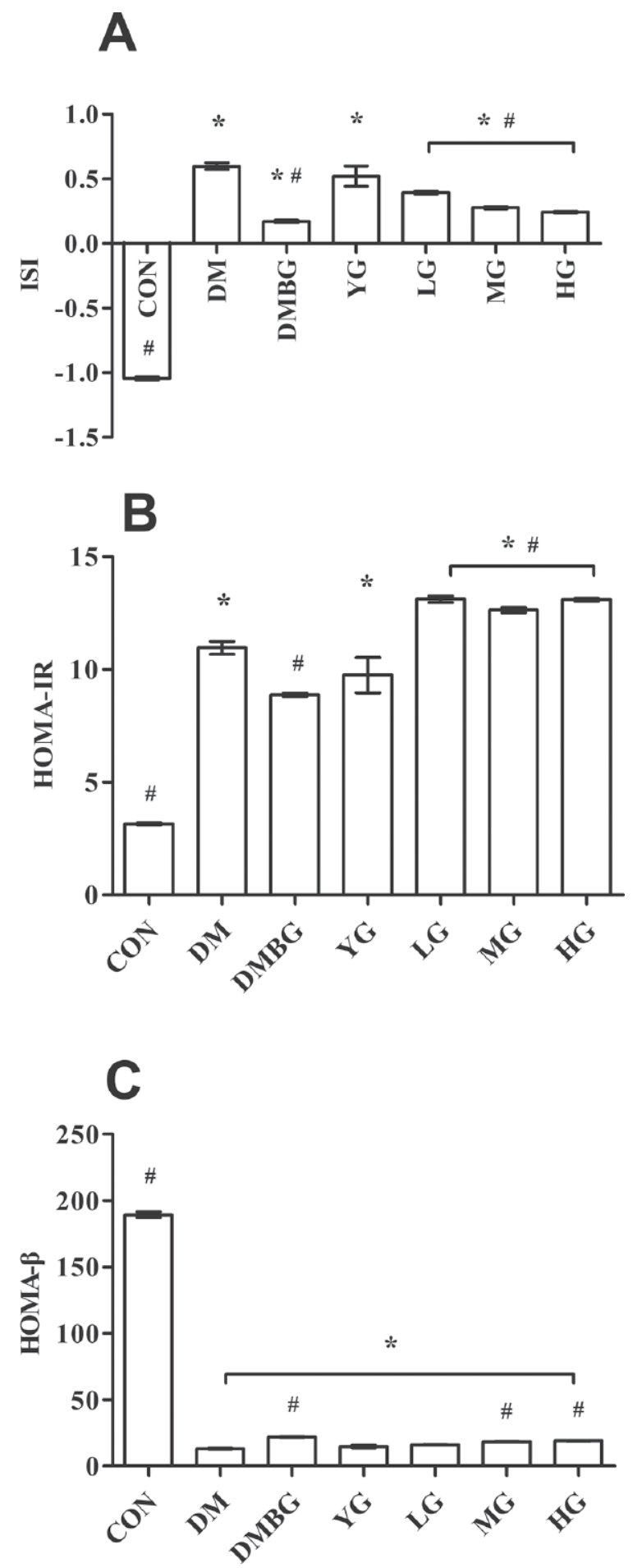

Figure 5. Effect of different dosages of $\gamma$-aminobutyric acid (GABA) yogurt on (A) insulin sensitivity index (ISI), (B) insulin resistance index (HOMA-IR), and (C) homeostasis model assessment- $\beta$ $($ HOMA- $\beta)$. Values are the mean $\pm \operatorname{SEM}(\mathrm{n}=4)$. $\# P<0.05$ versus the DM group; ${ }^{*} P<0.05$ versus the $\mathrm{CON}$ group. $\mathrm{CON}=$ normal diet and water; $\mathrm{DM}=$ high-fat diet and water; $\mathrm{DMBG}=$ high-fat diet plus melbine; YG = high-fat diet plus yogurt without GABA; LG = highfat diet plus yogurt with low-dose GABA $(0.5 \mathrm{~g} / \mathrm{L}) ; \mathrm{MG}=$ high-fat diet plus yogurt with medium-dose GABA $(1 \mathrm{~g} / \mathrm{L}) ; \mathrm{HG}=$ high-fat diet plus yogurt with high-dose GABA $(2 \mathrm{~g} / \mathrm{L})$. 
was consistent with the administration of Lactobacillus rhamnosus CCFM0528 (Chen et al., 2014; Aryana and Olson, 2017). Compared with LG, the effects of MG and $\mathrm{HG}$ on decreasing insulin resistance resulted in an increase of HOMA- $\beta$.

In addition to modulating insulin sensitivity, the supplementation with GABA yogurt might lead to a improvement in renal function by decreasing BUN levels in patients with diabetes. Previous studies have suggested that probiotic fermented carrot juice improved kidney function in patients with diabetes by reducing the levels of BUN, creatinine, and uric acid ( $\mathrm{Li}$ et al., 2014). Our results showed that GABA yogurt treatment decreased BUN concentration and kidney coefficient in diabetic mice.

\section{CONCLUSIONS}

Dietary supplementation with GABA yogurt enhanced insulin sensitivity by decreasing the fat and
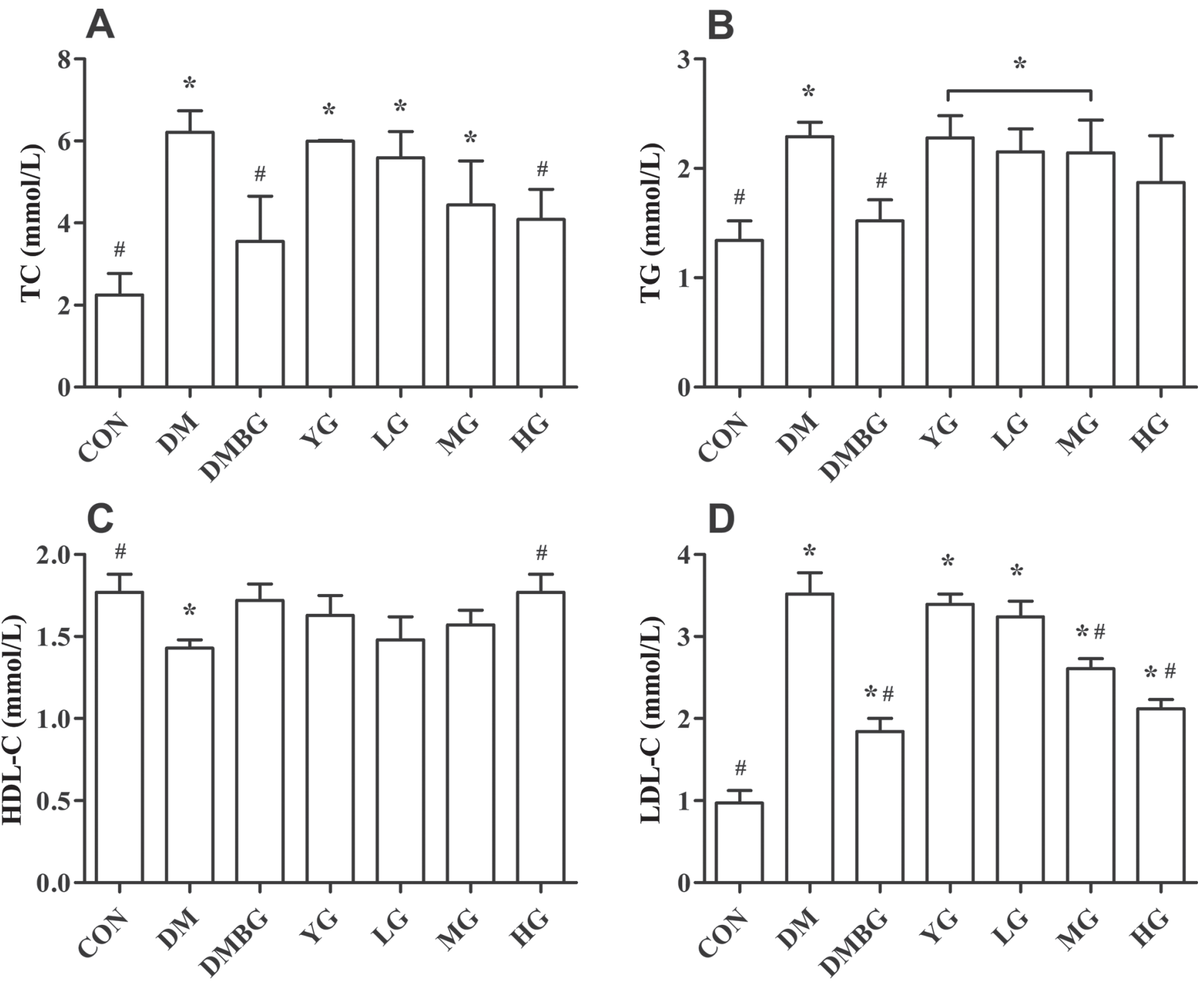

Figure 6. Effect of different dosages of $\gamma$-aminobutyric acid (GABA) yogurt on (A) total cholesterol (TC), (B) triglycerides (TG), (C) highdensity lipoprotein cholesterol (HDL-C) and (D) low-density lipoprotein cholesterol (LDL-C) levels. Values are the mean \pm SEM $(\mathrm{n}=5)$. \#P< 0.05 versus the $\mathrm{DM}$ group; ${ }^{*} P<0.05$ versus the $\mathrm{CON}$ group. $\mathrm{CON}=$ normal diet and water; $\mathrm{DM}=$ high-fat diet and water; $\mathrm{DMBG}=$ high-fat diet plus melbine; $\mathrm{YG}=$ high-fat diet plus yogurt without $\mathrm{GABA} ; \mathrm{LG}=$ high-fat diet plus yogurt with low-dose $\mathrm{GABA}(0.5 \mathrm{~g} / \mathrm{L}) ; \mathrm{MG}=\mathrm{high}-$ fat diet plus yogurt with medium-dose GABA $(1 \mathrm{~g} / \mathrm{L}) ; \mathrm{HG}=$ high-fat diet plus yogurt with high-dose GABA $(2 \mathrm{~g} / \mathrm{L})$. 
A

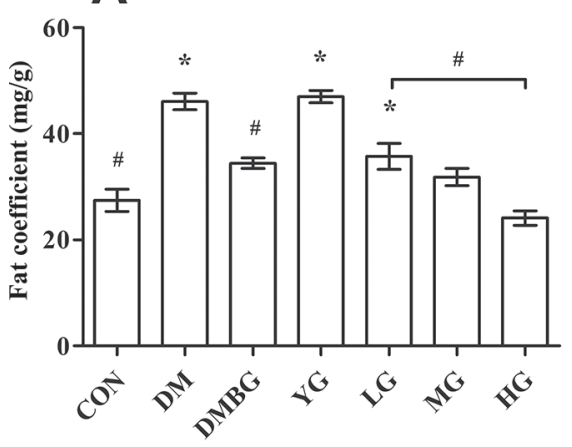

D

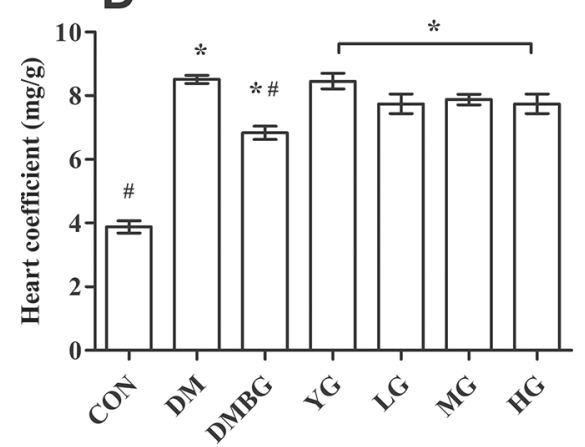

B

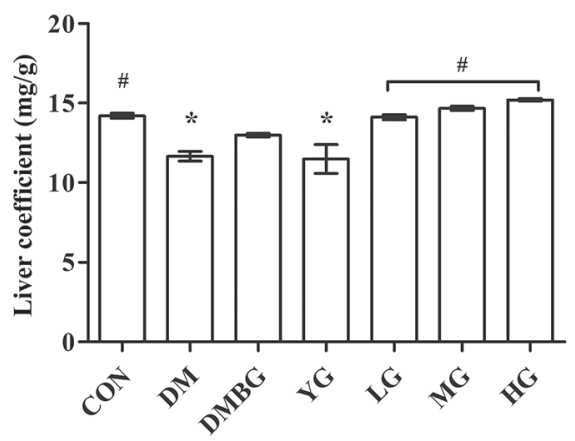

E

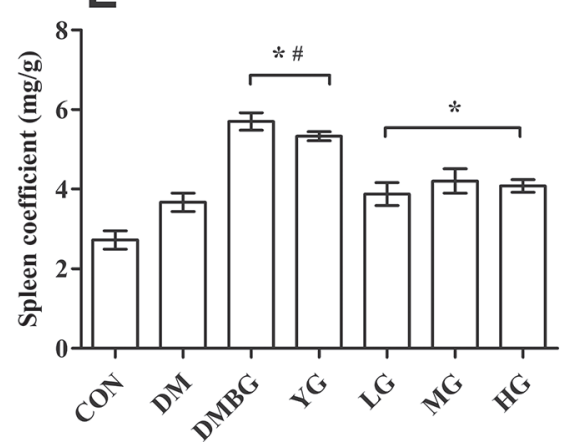

C
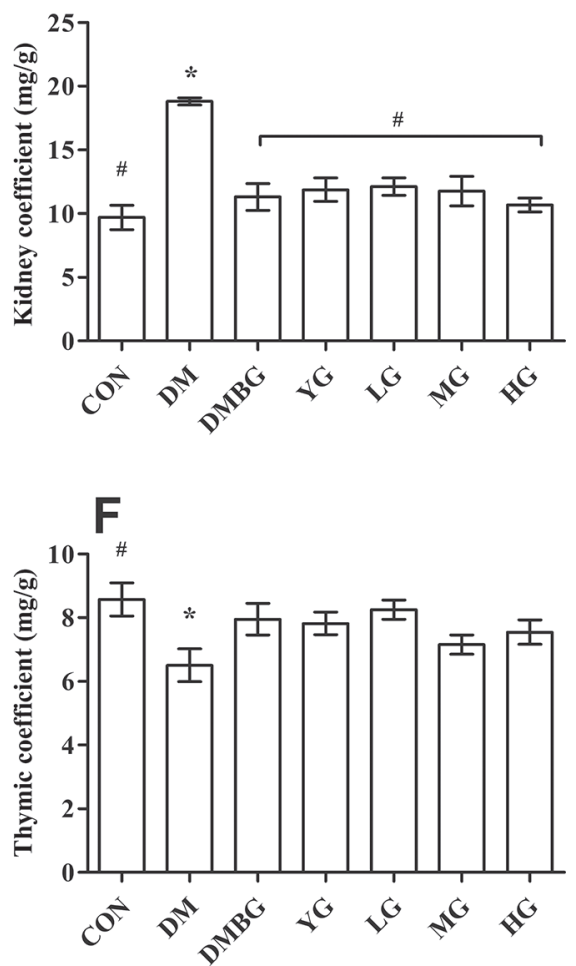

Figure 7. Effect of different dosages of $\gamma$-aminobutyric acid (GABA) yogurt on (A) fat coefficient, (B) liver coefficient, (C) kidney coefficient, (D) heart coefficient, (E) spleen coefficient, and (F) thymic coefficient levels. Organ coefficients were calculated as follows: organ coefficient $=$ organ weight/BW. Values are the mean $\pm \operatorname{SEM}(\mathrm{n}=4)$. $\# P<0.05$ versus the DM group; $* P<0.05$ versus the CON group. CON $=$ normal diet and water; $\mathrm{DM}=$ high-fat diet and water; $\mathrm{DMBG}=$ high-fat diet plus melbine; $\mathrm{YG}=$ high-fat diet plus yogurt without $\mathrm{GABA}$; LG = high-fat diet plus yogurt with low-dose GABA $(0.5 \mathrm{~g} / \mathrm{L}) ; \mathrm{MG}=$ high-fat diet plus yogurt with medium-dose GABA $(1 \mathrm{~g} / \mathrm{L}) ; \mathrm{HG}=$ high-fat diet plus yogurt with high-dose GABA $(2 \mathrm{~g} / \mathrm{L})$.
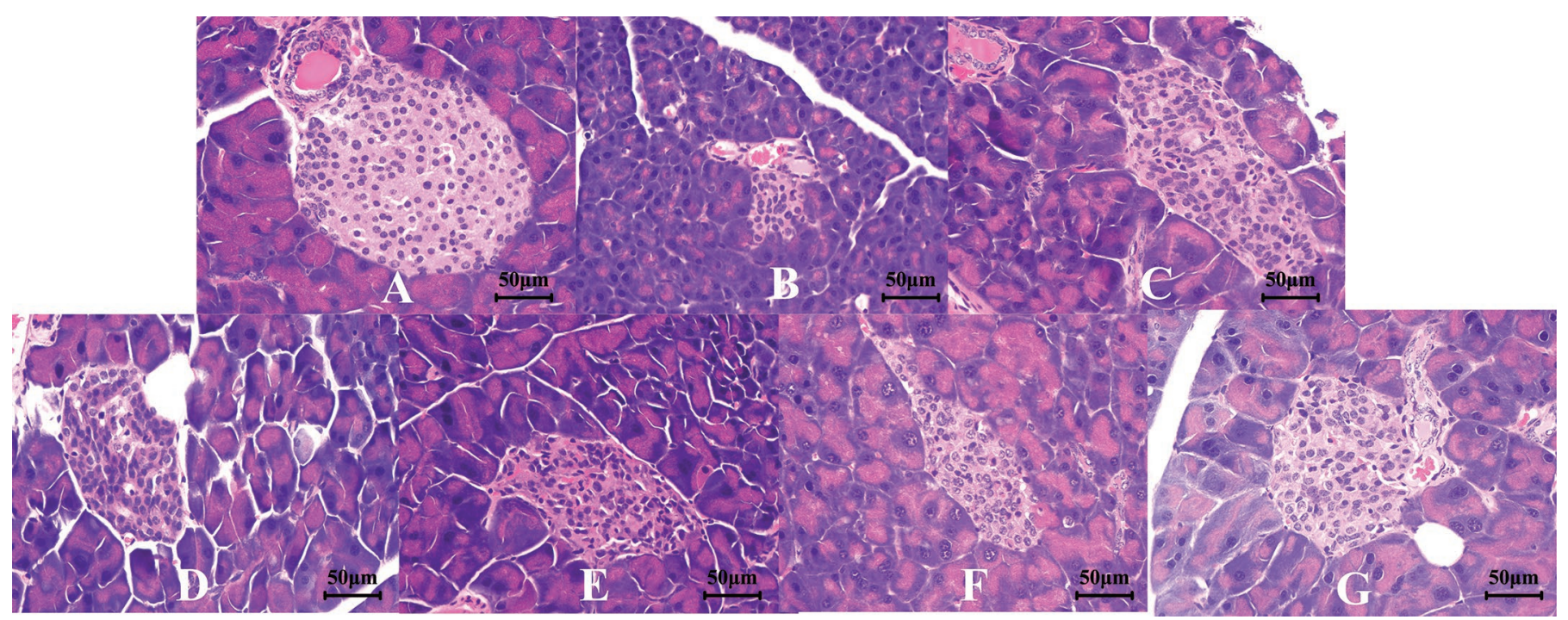

Figure 8. Effect of different dosages of $\gamma$-aminobutyric acid (GABA) yogurt on histopathology (magnification, 400×) of the pancreas. (A) CON group (normal diet and water), (B) DM group (high-fat diet and water), (C) DMBG group (high-fat diet plus melbine), (D) YG group (high-fat diet plus yogurt without GABA), (E) LG group (high-fat diet plus yogurt with low-dose GABA, $0.5 \mathrm{~g} / \mathrm{L}$ ), (F) MG group (high-fat diet plus yogurt with medium-dose GABA, $1 \mathrm{~g} / \mathrm{L}$ ), (G) HG group (high-fat diet plus yogurt with high-dose GABA, 2 g/L). 
kidney weight, increasing liver weight, regulating serum lipids, repairing damaged pancreas and improving glucose tolerance. The improved results of the OGTT may reflect repair of the pancreas by supplementation with GABA yogurt. Both middle and high doses of GABAyogurt could more effectively ameliorate insulin resistance than did the low dose. These results suggested that yogurt with a high concentration of GABA could be an effective supplement to enhance insulin sensitivity in patients with T2DM.

\section{ACKNOWLEDGMENTS}

This work was supported by the National Natural Science Foundation of China (No. 31801545), Natural Science Foundation of Jiangsu Province (SBK2018042932), Natural Science Research Projects of Jiangsu Higher Education Institutions (17KJB550005). The authors have not stated any conflicts of interest.

\section{REFERENCES}

American Diabetes Association. 2011. Diagnosis and classification of diabetes mellitus. Diabetes Care 34(Suppl 1):S62-S69. https://doi .org/10.2337/dc11-S062.

American Diabetes Association. 2013. Diagnosis and classification of diabetes mellitus. Diabetes Care 36(Supp_1):S67-S74. https://doi .org $/ 10.2337 / \mathrm{dc} 13-\mathrm{S} 067$.

Andreasen, A. S., N. Larsen, T. Pedersen-Skovsgaard, R. M. Berg, K. Moller, K. D. Svendsen, M. Jakobsen, and B. K. Pedersen. 2010. Effects of Lactobacillus acidophilus NCFM on insulin sensitivity and the systemic inflammatory response in human subjects. Br. J. Nutr. 104:1831-1838. https://doi.org/10.1017/ S0007114510002874.

Aryana, K. J., and D. W. Olson. 2017. A 100-Year Review: Yogurt and other cultured dairy products. J. Dairy Sci. 100:9987-10013. https: //doi.org/10.3168/jds.2017-12981.

Biessels, G. J., L. P. Van der Heide, A. Kamal, R. L. Bleys, and W. H. Gispen. 2002. Ageing and diabetes: Implications for brain function. Eur. J. Pharmacol. 441:1-14. https://doi.org/10.1016/S0014 -2999(02)01486-3.

Chen, P., Q. X. Zhang, H. Dang, X. M. Liu, F. W. Tian, J. X. Zhao, Y. Q. Chen, H. Zhang, and W. Chen. 2014. Oral administration of Lactobacillus rhamnosus CCFM0528 improves glucose tolerance and cytokine secretion in high-fat-fed, streptozotocin-induced type 2 diabetic mice. J. Funct. Foods 10:318-326. https://doi.org/10 $.1016 / j . j f f .2014 .06 .014$.

Daems, C., S. Welsch, H. Boughaleb, J. Vanderroost, A. Robert, E. Sokal, and P. A. Lysy. 2019. Early treatment with empagliflozin and GABA improves beta-cell mass and glucose tolerance in streptozotocin-treated mice. J. Diabetes Res. 2019:2813489. https://doi .org/10.1155/2019/2813489.

Feng, A. L., Y. Y. Xiang, L. Gui, G. Kaltsidis, Q. Feng, and W. Y. Lu. 2017. Paracrine GABA and insulin regulate pancreatic alpha cell proliferation in a mouse model of type 1 diabetes. Diabetologia 60:1033-1042. https://doi.org/10.1007/s00125-017-4239-x.

Gao, Y., M. Zhang, T. Wu, M. Xu, H. Cai, and Z. Zhang. 2015. Effects of D-pinitol on insulin resistance through the PI3K/Akt signaling pathway in type 2 diabetes mellitus rats. J. Agric. Food Chem. 63:6019-6026. https://doi.org/10.1021/acs.jafc.5b01238.

Haffner, S. M., A. S. Greenberg, W. M. Weston, H. Chen, K. Williams, and M. I. Freed. 2002. Effect of rosiglitazone treatment on nontraditional markers of cardiovascular disease in patients with type 2 diabetes mellitus. Circulation 106:679-684. https://doi.org/ 10.1161/01.CIR.0000025403.20953.23.

Hwang, I., K. Jo, K. C. Shin, J. I. Kim, Y. Ji, Y. J. Park, J. Park, Y. G. Jeon, S. Ka, S. Suk, H. L. Noh, S. S. Choe, A. A. Alfadda, J. K. Kim, S. Kim, and J. B. Kim. 2019. GABA-stimulated adiposederived stem cells suppress subcutaneous adipose inflammation in obesity. Proc. Natl. Acad. Sci. USA 116:11936-11945. https://doi .org/10.1073/pnas.1822067116.

Jones, N., L. M. Riby, R. L. Mitchell, and M. A. Smith. 2014. Type 2 diabetes and memory: Using neuroimaging to understand the mechanisms. Curr. Diabetes Rev. 10:118-123. https://doi.org/10 .2174/1573399810666140425160811.

Kahn, S. E. 2003. The relative contributions of insulin resistance and beta-cell dysfunction to the pathophysiology of Type 2 diabetes. Diabetologia 46:3-19. https://doi.org/10.1007/s00125-002-1009-0.

Kittler, J. T., and S. J. Moss. 2003. Modulation of GABAA receptor activity by phosphorylation and receptor trafficking: implications for the efficacy of synaptic inhibition. Curr. Opin. Neurobiol. 13:341-347. https://doi.org/10.1016/S0959-4388(03)00064-3.

Li, C., Q. Ding, S. P. Nie, Y. S. Zhang, T. Xiong, and M. Y. Xie. 2014. Carrot juice fermented with Lactobacillus plantarum NCU116 ameliorates type 2 diabetes in rats. J. Agric. Food Chem. 62:1188411891. https://doi.org/10.1021/jf503681r.

Li, X., E. Wang, B. Yin, D. Fang, P. Chen, G. Wang, J. Zhao, H. Zhang, and W. Chen. 2017. Effects of Lactobacillus casei CCFM419 on insulin resistance and gut microbiota in type 2 diabetic mice. Benef. Microbes 8:421-432. https://doi.org/10.3920/BM2016.0167.

Li, X., N. Wang, B. Yin, D. Fang, J. Zhao, H. Zhang, G. Wang, and W. Chen. 2016a. Lactobacillus plantarum X1 with $\alpha$-glucosidase inhibitory activity ameliorates type 2 diabetes in mice. RSC Advances 6:63536-63547. https://doi.org/10.1039/C6RA10858J.

Li, X., Q. Xu, T. Jiang, S. Fang, G. Wang, J. Zhao, H. Zhang, and W. Chen. 2016b. A comparative study of the antidiabetic effects exerted by live and dead multi-strain probiotics in the type 2 diabetes model of mice. Food Funct. 7:4851-4860. https://doi.org/10 .1039/C6FO01147K.

Manaer, T., L. Yu, Y. Zhang, X. J. Xiao, and X. H. Nabi. 2015. Antidiabetic effects of shubat in type 2 diabetic rats induced by combination of high-glucose-fat diet and low-dose streptozotocin. J. Ethnopharmacol. 169:269-274. https://doi.org/10.1016/j.jep.2015 .04 .032 .

Marques, T. M., E. Patterson, R. Wall, O. O'Sullivan, G. F. Fitzgerald, P. D. Cotter, T. G. Dinan, J. F. Cryan, R. P. Ross, and C. Stanton. 2016. Influence of GABA and GABA-producing Lactobacillus brevis DPC 6108 on the development of diabetes in a streptozotocin rat model. Benef. Microbes 7:409-420. https://doi.org/ 10.3920/BM2015.0154

Naito, E., Y. Yoshida, K. Makino, Y. Kounoshi, S. Kunihiro, R. Takahashi, T. Matsuzaki, K. Miyazaki, and F. Ishikawa. 2011. Beneficial effect of oral administration of Lactobacillus casei strain Shirota on insulin resistance in diet-induced obesity mice. J. Appl. Microbiol. 110:650-657. https://doi.org/10.1111/j.1365-2672.2010 $.04922 . x$

Salas-Salvadó, J., M. A. Martinez-Gonzalez, M. Bullo, and E. Ros. 2011. The role of diet in the prevention of type 2 diabetes. Nutr. Metab. Cardiovasc. Dis. 21(Suppl 2):B32-B48. https://doi.org/10 .1016/j.numecd.2011.03.009.

Soltani, N., H. Qiu, M. Aleksic, Y. Glinka, F. Zhao, R. Liu, Y. Li, N. Zhang, R. Chakrabarti, T. Ng, T. Jin, H. Zhang, W. Y. Lu, Z. P. Feng, G. J. Prud'homme, and Q. Wang. 2011. GABA exerts protective and regenerative effects on islet beta cells and reverses diabetes. Proc. Natl. Acad. Sci. USA 108:11692-11697. https://doi .org/10.1073/pnas.1102715108.

Taneera, J., Z. Jin, Y. Jin, S. J. Muhammed, E. Zhang, S. Lang, A. Salehi, O. Korsgren, E. Renstrom, L. Groop, and B. Birnir. 2012. Gamma-aminobutyric acid (GABA) signalling in human pancreatic islets is altered in type 2 diabetes. Diabetologia 55:1985-1994. https://doi.org/10.1007/s00125-012-2548-7.

Thielen, J. W., S. Gancheva, D. Hong, S. Rohani Rankouhi, B. Chen, M. Apostolopoulou, E. Anadol-Schmitz, M. Roden, D. G. Norris, 
and I. Tendolkar. 2019. Higher GABA concentration in the medial prefrontal cortex of Type 2 diabetes patients is associated with episodic memory dysfunction. Hum. Brain Mapp. 40:4287-4295. https://doi.org/10.1002/hbm.24702.

Tian, J., H. N. Dang, J. Yong, W. S. Chui, M. P. G. Dizon, C. K. Y. Yaw, and D. L. Kaufman. 2011. Oral treatment with $\gamma$-aminobutyric acid improves glucose tolerance and insulin sensitivity by inhibiting inflammation in high fat diet-fed mice. PLoS One 6:e25338. https://doi.org/10.1371/journal.pone.0025338.

Wang, G., X. Li, J. Zhao, H. Zhang, and W. Chen. 2017. Lactobacillus casei CCFM419 attenuates type 2 diabetes via a gut microbiota dependent mechanism. Food Funct. 8:3155-3164. https://doi.org/ 10.1039/c7fo00593h.

Xie, Z., T. Loi Truong, P. Zhang, F. G. Xu, X. J. Xu, and P. Li. 2015. Dan-Qi prescription ameliorates insulin resistance through overall corrective regulation of glucose and fat metabolism. J. Ethnopharmacol. 172:70-79. https://doi.org/10.1016/j.jep.2015.05.041.

Zhao, Y., X. B. Yang, D. Y. Ren, D. Y. Wang, and Y. Xuan. 2014. Preventive effects of jujube polysaccharides on fructose-induced insulin resistance and dyslipidemia in mice. Food Funct. 5:17711778. https://doi.org/10.1039/C3FO60707K.

\section{ORCIDS}

Xiangfei Li ( $\odot$ https://orcid.org/0000-0001-7258-295X

Zhaoxin Lu @ https://orcid.org/0000-0001-9288-7419 